\title{
Pensar o ensino de Geografia como algo feito por comentaristas de textos sagrados
}

\section{Reflecting on the teaching of Geography as something done by commentators of sacred texts}

\author{
Bruno Nunes Batista*
}

\begin{abstract}
RESUMO
Este artigo trabalha o ensino de Geografia e a prática docente a partir das ferramentas de Michel Foucault, relacionadas às formações discursivas, em geral, e ao comentário, em particular. A vontade de saber orbita em torno de entender quais os regimes de verdade que compõem essa disciplina escolar. Percorrendo textos da primeira metade do século XX até os dias atuais, a partir de uma descrição panorâmica dos seus discursos, constatou-se que a verdade da Geografia escolar vai da Queda à Redenção. Entende-se por Queda a extinção desse campo do conhecimento, capitaneado pela metodologia tradicional de ensino; e por Redenção levar a bom termo as descobertas das psicologias escolares e as pedagogias ativas. No meio de tudo isso, o resultado é um discurso amarrado por palavras sagradas, dividindo o certo e o errado, e que vem fazendo dos escritos escolares um jogo de cartas marcadas, coordenado por intelectuais.
\end{abstract}

Palavras-chave: Ensino de Geografia. Comentário. Discurso. Verdade.

\begin{abstract}
This article deals with the teaching of Geography, and teaching practice, starting from the tools of Michel Foucault as related to discursive formations, in general, and to commentary, in particular. The wish for knowledge orbits around understanding the truth regimes that compose this school subject. Going through texts from the first half of the twentieth century to the present day, from a panoramic description of their speeches, it was verified that

* Instituto Federal de Educação, Ciência e Tecnologia Catarinense. Blumenau, Santa Catarina, Brasil. E-mail: brunonunes.86@hotmail.com. https://orcid.org/0000-0002-3862-1465
\end{abstract}


the truth of school Geography goes from Fall to Redemption. By Fall, we mean the extinction of this field of knowledge, captained by the traditional teaching methodology; by redemption we mean bringing to fruition the discoveries of school psychologies and active pedagogies. In the midst of all this, the result is a discourse bound by sacred words, dividing right and wrong, and that has been making school writings a game of loaded dice, coordinated by intellectuals.

Keywords: Teaching Geography. Commentary. Discourse. Truth.

Antes que o professor comece a dar a sua aula, dela pode ser dito tudo, menos que se trata de "a sua aula"; pois a aula está cheia, atual ou virtualmente, de dados; os quais levam o professor a dar uma aula que já está dada, antes que ele a dê.

Sandra Mara Corazza

\section{Posturas preliminares}

Valho-me, iniciando esse texto, de algumas linhas apontadas por Theodor Adorno em uma conferência no ano de 1959. Transcrita e intitulada como "Tabus a respeito do professor", ela nos dá uma interessante perspectiva para trabalharmos sobre os escombros de uma prática pedagógica marginalizada, em certos momentos idealizada, mas raramente analisada no regime de verdade que a mantém: a do professor de Geografia.

$\mathrm{Na}$ fala de Adorno, o princípio que inicia sua exposição é a preocupação que ele partilha com seus ouvintes da baixa atratividade do magistério, representada como uma profissão sem reconhecimento social. Para ele - tomando o cuidado de se referir ao professor da escola básica, cuja imagem é pejorativamente diferente daquele que leciona no ensino superior -, essa rejeição decorre de raízes profundas fincadas entre a passagem da Idade Média ao início do Renascimento, quando vai se massificando a função do professor; essa posição social, contudo, não foi criada num piscar de olhos, visto que "[...] o professor foi um herdeiro do escriba" (ADORNO, 1992, p. 86), ou uma atividade ao qual recorriam "[...] soldados inválidos" (ADORNO, 1992, p. 92). Aqueles que adentraram nessa profissão se limitavam a reproduzir algo já estabelecido, sem intenção de proporem algo novo ou modificarem criativamente algo que estava posto; talvez seja daí que, como pontua Adorno (ADORNO, 1992, p. 
90), essa função tenha se tornado "[...] socialmente um pouco suspeita, tenha atraído certa aversão generalizada".

Ora, as palavras do pensador da Escola de Frankfurt não seriam, para aqueles que se debruçam sobre os arranjos escolares, nenhuma novidade. Sabe-se da baixa atratividade atual que o magistério exerce sobre as jovens gerações. Do mesmo modo, é pauta de inúmeras pesquisas, seja o denuncismo decorrente da acomodação docente, seja a construção de trabalhos didáticos que almejem melhorar as aulas. Por último, dizer que a criatividade deve estar presente é uma afirmação que poucos ousariam contestar. Até aqui, portanto, nada de novo.

Ao seguir a leitura de Adorno, ou seja, acatando que o discreto status da carreira docente emergiria da sua pequena possibilidade autoral, a pegada aqui será, no entanto, outra. Isso porque se dizemos - frequentemente... - que as teorias educacionais vêm avançando, que o professor resiste em aplicá-las, e que, como resultado, o ensino se manteria em estado precário, o que raramente fazemos é torcermos a reflexão perante a própria teoria. Fazendo-o, talvez as coisas ficassem interessantes. No caso do ensino de Geografia, isso vem sendo bem interessante. Afinal, de uma pesquisa oriunda de uma tese de doutorado, tenho procurado tomar esse campo do conhecimento quanto discurso, no sentido elencado por Michel Foucault, sendo assim um campo sobre o qual "[...] não se tem o direito de dizer tudo, que não se pode falar de tudo em qualquer circunstância, que qualquer um, enfim, não pode falar de qualquer coisa" (FOUCAULT, 1996, p. 9). Desse jeito, existiria nos ditos e escritos da Geografia estatuto legal que seccionaria o certo e o errado, o normal e o anormal e, por conseguinte, edificaria uma verdade do ensino e da aprendizagem dessa disciplina.

Esse texto seguirá os contornos delineados por Theodor Adorno não para denunciar a covardia de inovar e o marasmo de educar do professor de Geografia nem, muito menos, para dizer como a aula deveria ser. O objetivo será modesto: centrar-se apenas no que vem sendo escrito e dito sobre essa disciplina escolar e colocar em análise algo um pouco doloroso de assumir: que se existe, no que toca ao ensino de Geografia, uma pasmaceira no que se faz, e/ou um medo de se "modernizar", esses quadros estariam sendo pintados também pelos experts pedagógicos, intelectuais que seguem as mesmas grades de inteligibilidade há bastante tempo construídas. Aplicando uma análise de discurso foucaultiana, o que não farei é, contudo, cair na vala comum do denuncismo educacional e apontar o dedo para esses autores. Afinal de contas, na companhia de Foucault como também de Nietzsche, mais vale pensar que se o que viemos escrevendo sobre a Geografia da escola se mantém, é porque estamos submetidos a um regime de verdade, pedágio pelo qual acabam passando as práticas linguísticas para serem autorizadas a existir. 
$\mathrm{O}$ artigo vai desenrolar-se por meio de três etapas. Na primeira delas, o objetivo é, a partir de alguns arcabouços teóricos pós-estruturalistas, apontar panoramicamente como algumas ideias discutidas por Michel Foucault e Jacques Derrida podem ser producentes para nos levar a bom termo à análise do discurso geoescolar. Feito isso, recorro a uma espécie de descrição de textos pedagógicos que percorrem, à maneira de um jogo de pingue-e-pongue, a primeira metade do século XX e a contemporaneidade. Dessa partida, teremos esboçado um quadro de como vem se falando e o que vem se falando sobre ensino de Geografia, nas últimas décadas, no Brasil. Finalmente, será discutido esse substrato enquanto uma produção histórica que engendrou uma verdade ministerial em torno da qual certas teorias vêm orbitando. Como algo feito nesse mundo, para esse mundo, a ideia é pensarmos esse discurso pedagógico como uma produção humana, demasiadamente humana, funcionamento através do qual não é possível deixar de esbarrarmos nele; porém, é a partir dessa ficção que podemos fazer alguma coisa.

\section{Algumas ferramentas operatórias}

A repetição das críticas, a continuidade de histórias semelhantes. O retorno às narrativas primeiras que, de tanto serem ditas e reditas, transformam-se em ladainhas. A âncora lançada sobre os mesmos solos solucionadores que pronunciam como a vida deve ser e, se for o caso, de não estar sendo, é porque as instruções não estão sendo cumpridas. A busca de um fim último, aquele que não muda e, no entanto, nunca chega, eterno vir a ser... Quem, no ensino de Geografia, já não teve a impressão de ter lido ideias em algum outro lugar, mais de uma, senão inúmeras vezes? Haveria algum estudioso dos estudos geográficos escolares que, no meio de uma respectiva leitura, não tenha feito o exercício de prever o que viria a ser escrito e... acertou?!? Ou, por último, algum de nós já não se encontrou em meio à escrita de um texto e se deu conta de que, para terminá-lo, deveria ser inserida tal premissa, levantando tal conceito a partir de tal autor?

Essas velhas sensações não se dão por acaso, tampouco por mera coincidência. O conjunto delas, nos sistemas de linguagem, chamemos de comentário (FOUCAULT, 1996). Essa noção se estreita ao pressuposto de que os discursos instituem reincidências, forças por meio das quais os textos vão se repetindo ainda que, superficialmente, pareçam variar; organizados por meio de fórmulas, determinam as regularidades em torno das quais o dizer e o escrever se movimentam e, assim, pronunciam-se à maneira daquele terreno linguístico 
original. Texto primeiro, espécie de estatuto que detém o sentido do discurso e que, por conseguinte, é reatualizável na sua repetição: deve-se, devido ao comentário, "[...] dizer pela primeira vez aquilo que, entretanto, já havia sido dito e repetir incansavelmente aquilo que, no entanto, não havia jamais sido dito" (FOUCAULT, 1996, p. 25).

O comentário se configura como um tipo de polícia discursiva, ao qual aqueles que vão referir-se a algum objeto devem obedecer às formas jurídicas pré-dispostas. Polícia à guisa de posto de pedágio ou limite institucional de fronteira, os quais ninguém entra "[...] se não satisfazer a certas exigências ou se não for, de início, qualificado para fazê-lo" (FOUCAULT, 1996, p. 37). Preço cobrado pelas "grandes verdades" e pelos "grandes autores" que elevam à visibilidade as narrativas que comentam seus textos primeiros, ou lançam ao esquecimento aqueles que almejam acionar o discurso de uma outra forma; de sorte que somos sujeitados pelos efeitos de "[...] uma aderência tal que acreditamos ser necessário passar por eles para poder dizer alguma coisa, já que sem eles nada teríamos a dizer" (CORAZZA, 1998, p. 198).

Nas pesquisas que ando realizando em torno dos arquivos do discurso geográfico-escolar, uma das frentes que vêm sendo desenvolvidas é a de pensar até que ponto no interior linguístico desse campo "[...] cada discurso se endereça a essa primeira escrita, cujo retorno ao mesmo tempo promete e desvia" (FOUCAULT, 1999, p. 57). Como resultado, uma reprise discursiva, remetida ao texto sagrado que contém a revelação. Ditos e escritos que colocam em operação uma prática estável que, fantasmagoricamente, regulamenta os ensaios discursivos subjacentes ao ensino da Geografia. Nesse sentido, a força desse "[...] comentário se detém perante o caráter íngreme do texto prévio e dá-se a tarefa impossível, sempre renovada, de repetir em si seu nascimento: sacraliza-o" (FOUCAULT, 1999, p. 111-112).

Encontrar o rastro discursivo que configura os comentários sacralizados nessa disciplina não passaria, no entanto, por uma intencionalidade cujo fim seria a destruição: é o oposto do que gostaria de fazer. Afinal, nesse jogo de cartas marcadas, a identificação da banca que nos impõe as taxas às quais somos tributários remeter-nos-ia ao conceito derridariano de arquivo. Segundo Derrida (2001), esse seria o conjunto de textos que estabelecem o início e o comando da linguagem, o lugar de onde a autoridade exerce o seu poder e a ordem é dada. No ensino de Geografia, existiriam então obras que determinariam as referências motrizes em torno das quais o currículo escolar é desenvolvido, traçando os limites ao modo de uma força de lei. É um engano pensar que, porém, esses arquivos seriam totalmente repressores de novidade: a figura do arquivo é, simultaneamente, instituidora e conservadora, ou seja, ela é tão revolucionária quanto tradicional. E tem que ser assim: sem sua existência 
“[...] não compreenderíamos nem mais como um ancestral pode falar de nós nem que sentido haveria para nós em falar dele" (DERRIDA, 2001, p. 50). O arquivo é uma responsabilidade e uma preservação; nada se faz sem arquivos o que é diferente do que dizer que eles não possam ser transformados. Por isso é fundamental conhecermos o alicerce original sob o qual elaboramos nossos fazeres e dizeres.

Transitando nessa grade de inteligibilidade com o intuito de rastrear como e de qual maneira vem sendo organizadas as estruturas discursivas na Geografia escolar, esquadrinharei os ferrolhos tocados pelos autores desse discurso ordenado. Antes disso, porém, quero rapidamente esclarecer por meio de qual caminho investigativo a empreitada se materializará. Ao invés de chamá-lo de método, prefiro situá-lo como uma perspectiva de trabalho.

\section{Perspectiva de trabalho}

Primeiro de tudo, é preciso apontar os textos sob os quais estarei me debruçando, grosso modo, eles estão organizados em duas famílias temporais.

Uma delas, centrada nos dizeres sobre ensino de Geografia da primeira metade do século XX, trabalha a partir do Boletim Geográfico. Trata-se de uma publicação do Instituto Brasileiro de Geografia e Estatística (IBGE) que circulou nos espaços acadêmicos do ano de 1943 até 1978, com periodicidade, em média, bimestral. Com tiragem de 10 mil exemplares por edição, circulando no território nacional com preço considerado acessível, constituiu a expressiva marca de 35 anos de editoração transmitidas por intermédio de 259 publicações (PRÉVE, 1989). Trazendo um espaço cativo destinado à educação geográfica - "Contribuição ao ensino" -, consolidou o IBGE como um veículo notório de formação de professores, haja vista o expressivo número de materiais editados, obras avulsas, eventos e cursos de férias ofertados para professores. Do mesmo modo, há que se destacar a presença cativa desses textos tanto nas bibliografias dos cursos de graduação em Geografia quanto nas dos livros didáticos produzidos durante a faixa de tempo na qual esteve circulando (PRÉVE, 1989). De fato, o Boletim Geográfico contribuiu para estabelecer os conteúdos presentes no currículo, uma metodologia de ensino e um padrão idealizado de professor de Geografia.

A segunda família tem como luneta a contemporaneidade do fazer geoescolar. Assim, optei por fazer um recorte de escritos a partir dos anos 1990. Essa decisão responde a duas circunstâncias: a primeira é a explosão de aportes teóricos 
publicados sobre essa linha de pesquisa a partir dessa década; a segunda, por sua vez, dá-se a partir do entendimento da proximidade temporal desses escritos, posto que estão presentes em ementas disciplinares nos cursos de graduação em licenciatura em Geografia, de forma que contribuem para um modelo de professor. Delimitando a análise para livros e artigos publicados em revistas nacionais, o espaço hachurado, contudo, segue o sistema métrico do Google Scholar. Sendo essa uma ferramenta que permite pesquisar trabalhos acadêmicos, literatura escolares, jornais de universidades e artigos variados, através de ordem de relevância (a frequência de citações na literatura acadêmica), pude aplicar uma metodologia de recorte. Fazendo uso de palavras-chave como "Ensino da Geografia", "Geografia escolar", "Educação Geográfica", chega-se a textos amplamente citados em resumos, trabalhos de conclusão de curso, dissertações, teses, artigos de editoras acadêmicas etc. É claro que esse universo de textos não permitiria tomá-los, um a um, na sua amplitude; é por isso que recorro a uma utilizada técnica da Pesquisa Qualitativa, a saturação. Desse jeito, a leitura dos textos é configurada por um movimento que se encerraria provisoriamente quando "[...] a inclusão de novos estratos não acrescentasse mais nada de novo" (BAUER, 2014, p. 59).

Finalmente, a postura que adoto perante esses dois arquivos. Como estou me ancorando na ideia de o ensino de Geografia ser estruturado enquanto um comentário, uma delimitação urgia ser elaborada. Nesse caso, construí-a do ponto de vista da subjetividade do professor e do aluno; portanto, motivado a perceber - tanto nos textos contemporâneos como naqueles do Boletim Geográfico - como discorreram a respeito de possibilidades de ensinar Geografia, problematizando sua didática e difundindo uma metodologia de ensino. Sendo assim, utilizei como instrumento de análise os dizeres que discutiam questões de ordem pedagógica e didática, empreendendo diálogos tanto ao nível da descrição de como se encontrava a Geografia escolar em um determinado momento, como compartilhando condições à melhora qualitativa das práticas escolares e, igualmente, à formação docente.

Agora é o momento de acompanharmos o que vem sendo identificado dessa vontade de saber.

\section{Da doutrina da queda às promessas de redenção: breve história do discurso geoescolar}

Para apresentar as principais linhas argumentativas que vêm sendo engendradas no bojo dos textos sobre ensino de Geografia, valer-me-ei da 
Alegoria da Caverna, pressuposto célebre da academia platônica que reverberava na Filosofia Antiga (GHIRALDELLI JR., 2011). Conforme essa historieta, operada também na Doutrina dos Dois Mundos ou na Teoria da Linha Dividida, a ideia é de que este mundo estaria separado entre uma sensibilidade e uma inteligibilidade, sendo aquela representada pela doxa (a opinião) e esta pela dianoia (conhecimento). Aqueles limitados pela doxa seriam os prisioneiros de uma escura caverna, que obscurecia sua visão e os fazia ver o mundo apenas nas suas formas visíveis; já os que atingiam o conhecimento se libertavam e não queriam voltar ao mundo das sombras, pois alcançaram a Forma do Bem.

Ora, no caso do ensino de Geografia, diversos substratos discursivos sinalizam que, nesse centenário discurso, a prática docente vem estando dividida entre um mundo inferior, ilustrado pela figura da didática tradicional, e um mundo superior, iluminado pelas pedagogias ativas e as descobertas científicas provenientes das psicologias escolares. No meio de tudo isso, aqueles fazeres reduzidos à doxa do mundo concreto levariam a disciplina à Queda, fim último que extinguiria a Geografia; por sua vez, o conhecimento abstrato salvaria essa prática profissional, cabendo aos professores, para tanto, que aplicassem as inovadoras prescrições com o objetivo de alcançarem a Redenção. Vamos ver isso em termos discursivos.

Um trampolim nesse diálogo pode ser iniciado pela similitude de raciocínio entre dois autores. Um deles é Vesentini (2004, p. 220), o qual afirma que "Ou a Geografia muda radicalmente e mostra que pode contribuir para formar cidadãos ativos, ou ela vai acabar virando peça de museu"; o outro é Monbeig (1955, p. 423), que, nos momentos iniciais da palestra de abertura de um evento no IBGE, avisa: "Estou aqui porque disseram que o ensino da Geografia está no momento seriamente ameaçado no Brasil". Trata-se de dois autores, ambos expoentes pensadores do ensino de Geografia que, em épocas diferentes, convergiam suas ideias num mesmo ponto: a precariedade dessa disciplina escolar. Parece que esse é um consenso que, discursivamente, vem se repetindo nas últimas décadas quando se discute tal campo de conhecimento.

A Queda tem um motivo principal: o jogo errático da presença e da ausência. Presença: do falho, instituído pela didática tradicional, o descritivismo e a avaliação mnemônica. São pautas desenroladas por diversos autores, em inúmeros tempos e espaços acadêmicos. Ausência: da didática moderna, das metodologias, das contribuições científicas, das recomendações das psicologias do desenvolvimento cognitivo.

Zarur (1941, p. 227-262) apontava a educação como uma das áreas mais conservadoras a reconhecer os avanços da ciência moderna. No que concerne à Geografia escolar, esta seria ensinada sem adotar métodos pedagógicos, princípios psicológicos e processos cognitivos. Assim, seria uma atividade 
carente de objetivos definidos e ausente de processos racionais de aprendizagem: pelo contrário, professores preocupavam-se apenas com a nomenclatura, na qual eram enumerados nomes geográficos sem nenhum objetivo que não a simplória memorização (ZARUR, 1941). Sem que os alunos encontrassem uma aplicação imediata daquele saber nas suas vidas, o resultado seria formar uma geração de educandos inimigos do pensamento geográfico. Em vista disso Zarur sugere evitar que se espere de crianças e adolescentes uma formação em nível de bacharelado; o aluno deve tornar-se parte da aula, visto que práticas de ensino socializantes proporcionam que o estudante avance não apenas no conhecimento da matéria, mas que adquira hábitos de convívio, responsabilidade e consciência social; logo, elaborando bases cidadãs. $\mathrm{O}$ autor encerra o texto alertando para a ineficiência daquela Geografia escolar que mais mede "[...] os recursos de memória do que o pensamento reflexivo e tolhe a capacidade de expressão livre do aluno, viciando a sua capacidade construtiva e organizadora" (ZARUR, 1941, p. 262).

Nada que não tenha sido escrito depois. Resende, nas suas investigações em espaços escolares da escola básica, encontrou nas aulas de Geografia um tipo de aluno visto "[...] como um ser neutro, sem vida, sem cultura, sem história, um ser que não trabalha nem produz riqueza" (RESENDE, 1993, p. 28)"; atividade que o marginalizava enquanto "[...] sujeito do processo de conhecimento e transforma-o em objeto desse processo" (RESENDE, 1993, p. 34). Constatação idem identificada por Fernandes (2008, p. 10), o qual afirmou que "[...] das coisas sem serventia uma delas é a Geografia", sendo um entre tantos "[...] desses negócios chatos que inventaram para ser a palmatória intelectual das crianças" (FERNANDES, 2008, p. 28). Castellar fala que as aulas de Geografia são, em geral, "[...] muito tradicionais e, talvez por isso, desorganizadas" (CASTELLAR, 2011, p. 74); a escola, com efeito, "[...] acrescenta pouco" (CASTELLAR, 2011, p. 71). Em consonância de opinião, as pesquisas de Goulart identificam que essa disciplina da escola "[...] tem sido ao longo de sua história um conhecimento relegado à condição de inutilidade" (GOULART, 2011, p. 19).

Cavalcanti (2008), por sua vez, descreve a existência de um conhecimento geográfico que não interessa aos alunos, conteúdos inúteis e sem significado. A memorização, para a autora, representa o principal método de ensino, portanto, acrítico e estático. Cavalcanti delibera a necessidade de oportunizar aos estudantes a chance de questionar tanto o conhecimento cotidiano quanto o científico, interligando-os. Remete tal metodologia a potencializar "[...] o desenvolvimento do pensamento abstrato, conceitual, crítico, indispensável para desmontar, por exemplo, uma falsa representação da realidade ou representações superficiais, ingênuas" (CAVALCANTI, 2008, p. 144). 
Essas questões, quarenta anos antes, seriam motivo de análise para Weiss, um autor que culpava a prática pedagógica tradicional pelas “"...] atitudes negativas do aluno, quando o obrigam a memorizar cabos, ilhas e cidades importantes que são o conteúdo de uma pseudo Geografia" (WEISS, 1962, p. 298). A resposta à problemática situação evocava que o professor de Geografia ensinasse o estudo das relações que a sociedade imprimia na paisagem, pressuposto que, contudo, dependia da "[...] renovação constante do professor, seja em conteúdo ou métodos" (WEISS, 1962, p. 299). Para tanto, esse profissional, segundo Monbeig (1945, p. 170), “[...] deve ter a curiosidade intelectual que se adquire pela pesquisa e deve ter recebido uma formação científica que lhe permita se manter à corrente do progresso da Geografia". Deve-se investir nas disciplinas técnico-pedagógicas nas licenciaturas, algo que estava longe de ser bem feito (MONBEIG, 1944). A qualificação do professor permaneceria sendo discutida muitos anos depois, como na fala de Cavalcanti (2012, p. 18-22), que se permite prescrever quais seriam os requisitos necessários a serem construídos por esse profissional: a formação constante, uma postura atenta à dinamicidade do mundo, um conhecimento interdisciplinar que extrapolasse a Geografia e se expandisse à cognição, ao afeto, às psicologias e aos suportes pedagógicos.

Backheuser já levantava a bandeira do denuncismo à didática no final da primeira metade do século $\mathrm{XX}$, sinalizando que o trabalho pedagógico convencional havia feito com que a Geografia se desmoralizasse "[...] pelas próprias mãos" (BACKHEUSER, 1943, p. 5). Carvalho, por seu turno, questionava o porquê de tantos professores não se deixarem "[...] convencer de que a Geografia não é mais esta encantadora lista que dispensava o uso da inteligência, da razão, do juízo ou do simples bom senso" (CARVALHO, 1945, p. 819). Já Mory, no que tange ao uso da inteligência, evidenciava a pertinência de coordenar um ensino que mobilizasse cognitivamente o estudante: "Se a criança é ativa, e descobre, em lugar de registrar, fica interessada, presa ao seu trabalho e executa-o com proveito e satisfação. É nesse sentido que os métodos ditos ativos renovam a Pedagogia" (MORY, 1947, p. 572). De forma semelhante, seis décadas depois, desenrola-se o raciocínio de Cavalcanti (2012), ao sair em defesa do que intitula de ideias-motrizes necessárias à mudança na educação geográfica, como o construtivismo como atitude básica ao trabalho pedagógico, a Geografia do aluno como ponto de partida referencial e a execução de conteúdos procedimentais e valorativos no planejamento de ensino.

Castellar e Vilhena concordariam: para elas, o mundo vivido pelo aluno the serve como engrenagem para a compreensão da esfera geográfica teórica; cabe ao professor fazer a transposição entre a realidade discente e o mundo científico, através de sucessivas problematizações; “[...] pesquisas, aulas expositivas, trabalho de campo etc. contribuirão para que o aluno consiga estruturar e 
construir conceitos científicos no campo do mundo teórico" (CASTELLAR; VILHENA, 2012, p. 100-101). Preocupações didáticas como as descritas pelas autoras, entretanto, não vêm de agora, vide as ilustrações acentuadas no texto de três autores do início da segunda metade do século XX: Boléu (1956, p. 288), descreve a importância do uso na sala de aula de instrumentos pedagógicos como o museu geográfico, o cinema, as projeções, os trabalhos manuais, os desenhos e as visitas de estudo; Cantão (1956) discorre sobre os tipos de excursões geográficas para fins didáticos, assim como os elementos procedimentais e técnicos a serem elaborados pelo professor; Espinheira (1957, p. 197-204), estabelece a tríade "ver, pesquisar e fazer" na experiência pedagógica, debruçando-se sobre materiais didáticos como as salas-ambiente, recursos de ensino e o uso da biblioteca.

Callai, recentemente, deliberou acerca das benesses alavancadas pelo ensino iniciado através do espaço vivido dos estudantes: “[...] é a Geografia estudando os lugares como sendo o resultado das ações humanas que, materializadas no espaço, concretizam espacialmente as relações" (CALLAI, 2011, p. 35). Com essa posição, resta-lhe acusar a insuficiência da Geografia que é apenas descritiva, afinal de contas "A análise do espaço deve ocorrer a partir de um vaivém constante entre a descrição, as relações, as explicações do aparente e a busca de justificativas desta aparência" (CALLAI, 2009, p. 99). Contudo, a preocupação de não apenas observar e descrever, mas também explicar, já existia com clareza em textos como o de Ficheux que apontava que os estudos geográficos deveriam promover situações nas quais os alunos aprendessem a ver com criticidade; através da "[...] observação atenta da constante comparação entre o que foi visto num lugar e o que existe fora dele que nascem o porquê, como, quando, onde" (FICHEUX, 1950a, p. 384).

Poderíamos, de natureza igual, hibridizar as ideias de Quintierre, para a qual a concepção moderna de aprendizagem sustenta que o aluno não mais escuta, memoriza e repete, mas trabalha, dando "[...] larga margem à inteligência imaginativa e viva do adolescente (QUINTIERRE, 1947, p. 1028)", com os dizeres de Pontuschka (2004). Segundo a última, "É preciso saber ver, saber dialogar com a paisagem, detectar os problemas existentes na vida de seus moradores, estabelecer relações entre os fatos verificados e o cotidiano do aluno" (PONTUSCHKA, 2004, p. 260). Ou, semelhantemente, formar uma relação entre os princípios geoescolares, que aparecem em diretrizes comuns tanto em Prado (1956, p. 392) quanto em Vesentini (2009, p. 51-52), como conhecer o espaço pela sua interpretação, fortalecer o espírito investigativo perante a realidade e capacitar o aluno à compreensão do mundo em que vive.

Callai apregoa a necessidade de superar o ensino de Geografia que só "passa conteúdos" aos alunos, de maneira que a aprendizagem possa ser significativa, 
pois é a partir do lugar que se pode compreender o mundo, mola de reflexão em torno da qual a escola faz sentido e "[...] a possibilidade de construir com os alunos um método de análise espacial que favoreça a construção da cidadania" (CALLAI, 2009, p. 132). Pauta que, importante de se pontuar, não havia escapado às apreensões de Fonseca: no momento em que advogava em prol da necessidade de, dialogando com o lugar, ensinar e aprender Geografia, abrir-se-iam espaços para fazer " $[\ldots]$ da escola um elemento comum da vida, ao contrário da atitude vulgar e errônea dos estudantes que encaram seus trabalhos escolares como uma vida à parte, destinados a fazer um curso apenas (FONSECA, 1963, p. 762)".

Já Cavalcanti, em duas comunicações, discute a potencialidade envolvida numa Geografia que contribua para a realidade imediata do estudante, um investimento que tende a forjar integralmente um "[...] cidadão democrático, ativo, criativo e consciente de seus direitos/deveres" (CAVALCANTI, 2012, p. 55); aluno com "[...] capacidade de pensar cientificamente e assumir atitudes éticas, dirigidas por valores humanos fundamentais, como justiça, solidariedade, reconhecimento da diferença, respeito à vida, ao ambiente, aos lugares, à cidade" (CAVALCANTI, 2012, p. 59). Aliás, nem outra via poderia haver, posto que, como sentenciava com segurança Cabral, caso o ensino de Geografia não se converta em "[...] maior discernimento na conduta dos alunos, face aos problemas sociais e políticos e em maior virtude nos modos de viver, então a aprendizagem não é efetiva" (CABRAL, 1958, p. 536).

Pontuschka se coloca na esteira desse posicionamento ao defender a centralidade no lugar do discente como pauta da aprendizagem. Afinal, tratase de um recurso propagandeado pela Escola Nova cujos resultados foram enriquecedores; quem diz isso são os alunos que estiveram no meio desse movimento: "[...] muitos hoje ocupam funções de liderança e em inúmeras oportunidades reportam-se ao significado para a sua formação global das escolas em que estudaram, nas quais o estudo do meio era priorizado" (PONTUSCHKA, 2004, p. 258). Mais um motivo, consequentemente, para o docente fazer uso desse instrumento apreensor da realidade; mais eficaz ele será, dizia já Prado (1956, p. 392), “[...] quanto maiores oportunidades der ao aluno para o desenvolvimento da sua personalidade. Este se faz por intermédio de reações contínuas ao ambiente, jamais por imposição do professor".

Como resultado desse enlace discursivo, estaria cabendo ao "bom" professor de Geografia ser, na síntese de Vesentini (2004, p. 224), “[...] aquele que aprende ensinando e que não ensina, mas ajuda os alunos a aprender - não apenas reproduz, mas também produz saber na atividade educativa". Da escola não devemos esperar que sejam produzidos pequenos geógrafos, mas, sim, cidadãos que dominem o ofício do "aprender a aprender" e, por conseguinte, insiram-se democrática e ativamente no mundo em que vivem. Por intermédio do centená- 
rio lema do "aprender a aprender" - presente aliás em elucubrações anteriores de Carvalho (1952), Pinto (1964) e Reeder (1950) -, alunos e professores vão acompanhando um mundo dinâmico, de imprevisíveis transformações e que, justamente por isso, requerem que a Geografia escolar apresente aos sujeitos escolares "[...] a realidade do mundo com suas exigências e possibilidades, e da mesma forma os deveres que incumbem a juventude para com o futuro" (FICHEUX, 1950b, p. 611).

Peças tecidas por uma mesma fiação, coloquei-me no papel de um professor que resolve problematizar um discurso pedagógico e, deste momento em diante, apresentei o resultado das condições concretas e abstratas no tocante ao ensino de Geografia que vêm sendo tocadas nas últimas décadas no Brasil. Movimento orientado em três direções, sendo elas a) descrições de um panorama; b) a vontade de aperfeiçoamento desse campo do conhecimento; c) um projeto de sociedade a ser alcançado. Substratos de ditos e escritos geopedagógicos que, agrupados por uma grade coesa de inteligibilidade, vêm carreando a subjetividade docente, os trabalhos de pesquisa, as discussões educacionais e, entrementes, uma verdade. Será que algum de nós, em algum momento, deixou de sacralizá-la?

\section{Para além do banal geoeducacional}

Talvez a principal herança que a Alegoria da Caverna tenha nos deixado foi o contínuo esforço de, frente ao que chamamos de realidade, antagonizá-la entre uma aparência e uma essência, sendo a segunda melhor que a primeira e, por isso, verdadeira. O pensamento moderno, balizado pelos auspícios da razão e validado apenas pelo que passasse pelas normas da ciência, aperfeiçoou essa atividade, busca última que ultrapassa as ilusões do mundo terreno.

Nietzsche (1999) tem, no entanto, uma visão diferente desse processo. Para o célebre filósofo, o produto desse confronto de dicotomias não seria nada mais do que uma convenção historicamente imposta, espécie de cruzada ao encontro de uma interpretação legítima que apreendesse a confusão da vida por meio de seguras leis. Nietzsche confere à esfera do vivido uma desorganização formadora de vida, de arte, de ineditismo; confluência embrulhada de incertos processos que, mesmo que quisesse, o intelecto não poderia acomodar. É nesse sentido que ele enxerga a verdade enquanto mera narrativa ficcional; portanto, questiona aquilo que é considerado verdadeiro e, para tanto, parte do posicionamento de que não existiria uma essência, mas, sim, uma crença disseminada por uma vontade de poder. 
Nietzsche diz que essas diretrizes universais nada mais são do que metáforas, relações humanas contingentes que foram canonizadas pela retórica e tornadas obrigatórias: desse jeito, restaria aos indivíduos, enquadrados aos termos da moral, afastarem de si sua vontade criadora e, consequentemente, "[...] mentir segundo uma convenção sólida, mentir em rebanho, em um estilo obrigatório para todos" (NIETZSCHE, 1999, p. 57). Posto que, na linha nietzschiana, a essência das coisas não existe e a vida reside no superficial, então as verdades nada mais seriam do que "[...] ilusões das quais se esqueceu que o são, metáforas que se tornaram gastas e sem força sensível, moedas que perderam sua efígie e agora só entram em consideração como metal, não mais como moedas" (NIETZSCHE, 1999, p. 57).

Ao olhar de um pouco mais de longe os ditos e escritos subjacentes ao ensino de Geografia que vêm sendo elaborados desde a aurora do século XX, pude partilhar algumas certezas pedagógicas centenárias dessa disciplina escolar. Comandos predestinados, teorias sacrossantas que, ditas e reditas, balizam a maneira como nos pronunciamos perante esse campo do conhecimento. Isso vem sendo feito através dos sistemas de linguagens, tomados aqui enquanto comentários de uma formação discursiva (FOUCAULT, 1987). Desse modo, o interessante é que a descrição desses raciocínios nos daria a oportunidade de descolá-los do lugar de verdade suprema e concebê-los como construções feitas em uma determinada época; por conseguinte, não existiria uma verdade na forma de ensinar e aprender Geografia, mas, sim, aquilo que é dado como verdade. A breve leitura de algumas palavras de ordem disseminadas por especialistas sinaliza uma espécie de narrativa, cujo percorrer é dado de saída e que, com efeito, faz dessa formação discursiva uma atividade, por vezes, previsível. Trata-se de um comentário coletivo que colocou uma espécie de direção geral com percursos, de antemão, conhecidos.

Para escrever e falar sobre esse componente curricular, autores teriam que denunciar o ensino arcaico, a memorização, o descritivismo: em suma, localizar no interior desse conhecimento uma doença, cujo remédio, entretanto, já existia. À maneira de farmacologia, esse foi manipulado pelas pedagogias progressistas e as psicologias experimentais e escolares; os intelectuais davam a receita, caberia aos professores aplicá-la ao seu paciente terminal. Se existe a obrigação de pronunciar-se de uma forma específica, não é qualquer um que, todavia, tinha o direito de fazê-lo - tal autoridade seria permitida, como diria Foucault (1987), pelas modalidades enunciativas que esse discurso era promotor. Nesse sentido, deve-se estar num lugar privilegiado, de respeitabilidade institucional, caso aquele que não se localize nessa posição, pagará pedágio a esses sujeitos proeminentes. Professores em sua maioria do meio universitário, acadêmicos nacionalmente reconhecidos, estudiosos de livre trânsito nos regimes de verdade da Pedagogia moderna, foram esses a dar o tom das discussões educacionais. 
Assim, só me resta retomar a leitura de Adorno para colocar que, quem sabe, talvez o profissional docente se porte, às vezes, como um copista, posição que depõe contra seu trabalho pedagógico e que pode ser uma das razões da sua subalterna representação social. No entanto, o que a descrição dos comentários relacionados ao ensino de Geografia nos mostrou é que esse processo é secundário e, muitas vezes, decorrente da ordenação ferrenha do discurso pedagógico, escalada sucessiva de pontos que o professor/pesquisador deve bater ao longo de uma corrida de cancha reta. Formação proveniente da dicotomia entre sensibilidade e inteligibilidade, engendra uma relação de proveniência entre os professores do "chão da escola" e aqueles que pensam teoricamente esse cotidiano. Por não serem considerados autores, aqueles têm status inferiores aos criadores da obra primeira, sendo subordinados a uma elaboração superior e inalcançada, visto que, na dicotomia entre teoria e prática, "[...] a supremacia do primeiro termo exige a supressão do segundo subordinado; de maneira que qualquer prática será sempre tomada como insatisfatória” (CORAZZA, 2015, p. 116).

$\mathrm{O}$ interessante disso é que, no que toca à sagrada obra original, preenchida pelas contribuições dos "especialistas", essa vem portando-se à maneira de inércia e parece que não raras vezes, na expressão de Morin (2011, p. 30), “[...] há mais opiniões pessoais diante do balcão de um café" do que nas publicações, seminários, encontros e congressos que objetivam discutir o desenvolvimento do ensino de Geografia.

A viagem no tempo pelos dizeres e fazeres geoescolares pode nos mostrar que do bojo de um discurso são dadas as ordens que obstaculizam o livre pensar e o ensinar por prazer, sendo essas molas propulsoras que fazem da aula uma experiência de vitalidade, deixando o conhecimento menos trivial. Arquivos que sufocam, porém, sem a compreensão da sua organização interna, tornam-se mais difíceis de contornar. Dessa maneira, este texto se deslocou como uma pequena contribuição no sentido de, frente ao marasmo discursivo, ilustrar que existiriam lacunas a ser preenchidas por emergentes vozes que problematizariam o pensamento docente, "[...] riscando, para começar, o nome do autor a fim de o substituir pelo seu" (NIETZSCHE, 2004, p. 81).

É claro que seria uma tremenda ingenuidade cogitar que essa ascendência de forças criativas emanaria da reacionária linguagem régia do "Ensino de Geografia Oficial". Também seria inocente a postura que pensasse que estarmos cientes desse estatuto nos conduzirá, num estalar de dedos, à melhor aprendizagem forjada pela super docência. Caminho longo, de vida-e-morte, audácia-precaução. Sem garantias, é verdade. Prefiro, contudo, essa incerta perspectiva a engrossar o público cativo do expert geoescolar; por ora, que ele pelo menos “[...] nos deixe livre quando se trata de escrever" (FOUCAULT, 1987, p. 20). 


\section{REFERÊNCIAS}

ADORNO, T. W. Tabus a respeito do professor. In: OLIVEIRA, N. R. de (Org.). Adorno: quatro textos clássicos. São Carlos/Araraquara: UFSCAR/UNESP, 1992.

BACKHEUSER, E. Tertúlias geográficas. Boletim do Conselho Nacional de Geografia, Rio de Janeiro, v. 1, n. 2, p. 5-8, maio 1943.

BAUER, M. A construção do corpus: um princípio para a coleta de dados qualitativos. In: BAUER, M. W.; GASKELL, G. (Orgs.). Pesquisa qualitativa com texto, imagem e som: um manual prático. Petrópolis: Vozes, 2014. p. 39-63.

BOLÉU, J. de O. Técnicas do ensino das Ciências Geográficas. Boletim Geográfico, Rio de Janeiro, v. 14, n. 132, p. 284-288, maio/jun. 1956.

CABRAL, E. F. O ensino de Geografia. Boletim Geográfico, Rio de Janeiro, v. 16, n. 145, p. 534-554, jul./ago. 1958.

CALLAI, H. C. Estudar o lugar para compreender o mundo. In: CASTROGIOVANNI, A. C. (Org.). Ensino de Geografia: práticas e textualizações no cotidiano. Porto Alegre: Mediação, 2009. p. 83-92.

CALLAI, H. C. A Geografia é ensinada nas séries iniciais? Ou: aprende-se Geografia nas séries iniciais? In: TONINI, I. M. et al. (Org.). O ensino de geografia e suas composições curriculares. Porto Alegre: UFRGS, 2011. p. 29-59.

CANTÃO, C. M. Programa: tipos de excursões geográficas para fins didáticos. Boletim Geográfico, Rio de Janeiro, v. 14, n. 134, p. 503-514, set./out. 1956.

CARVALHO, D. de. Compêndios e ilustrações. Boletim Geográfico, Rio de Janeiro, v. 3, n. 30, p. 817-820, set. 1945 .

CARVALHO, D. de. As Ciências Sociais e a aprendizagem. Boletim Geográfico, Rio de Janeiro, v. 10, n. 107, p. 232-235, mar./abr. 1952.

CASTELLAR, S. Mudança na prática docente: a aprendizagem em espaços não-formais. In: CASTROGIOVANNI, A. C.; KAERCHER, N. A.; REGO, N. (Orgs.). Geografia: práticas pedagógicas para o ensino médio (volume 2). Porto Alegre: Penso, 2011. p. 69-92.

CASTELlAR, S.; VILHENA, J. Ensino de Geografia. São Paulo: Cengage Learning, 2012.

CAVALCANTI, L. de S. A geografia escolar e a cidade: Ensaios sobre o ensino de Geografia para a vida urbana cotidiana. Campinas: Papirus, 2008.

CAVAlCANTI, L. de S. O ensino de Geografia na escola. Campinas: Papirus, 2012.

CORAZZA, S. M. História da infantilidade: a-vida-a-morte e mais-valia de uma infância sem fim. 1998. Tese (Doutorado em Educação) - Faculdade de Educação, UFRGS. Porto Alegre, 1998. 
CORAZZA, S. M. Didaticário de criação: aula cheia. Porto Alegre: Editora da UFRGS, 2012.

CORAZZA, S. M. Didática da tradução, transcriação do currículo (uma escrileitura da diferença). Proposições, São Paulo, n. 76, p. 105-122, jan./abr. 2015.

DERRIDA, J. Mal de arquivo: uma impressão freudiana. Rio de Janeiro: Relume Dumará, 2001.

ESPINHEIRA, A. Geografia. Boletim Geográfico, Rio de Janeiro, v. 15, n. 137, p. 195210, mar./abr. 1957.

FERNANDES, M. Aula de Geografia e algumas crônicas. Campina Grande: Bagagem, 2008.

FICHEUX, M. R. Ensino da Geografia II. Boletim Geográfico, Rio de Janeiro, v. 8, n. 86, p. 229-234, maio 1950a.

FICHEUX, M. R. Ensino da Geografia IV. Boletim Geográfico, Rio de Janeiro, v. 8, n. 89 , p. 602-612, ago. 1950 b.

FONSECA, J. V. Como ensinar Geografia. Boletim Geográfico, Rio de Janeiro, v. 22, n. 177, p. 759-763, nov./dez. 1963.

FOUCAULT, M. A arqueologia do saber. Rio de Janeiro: Forense-Universitária, 1987.

FOUCAULT, M. A ordem do discurso: aula inaugural no Collège de France pronunciada em 2 de dezembro de 1970. São Paulo: Edições Loyola, 1996.

FOUCAULT, M. As palavras e as coisas: uma arqueologia das ciências humanas. São Paulo: Martins Fontes, 1999.

GHIRALDELLI JR., P. Dossiê Platão. São Paulo: Universo dos Livros, 2011.

GOULART, L. Aprendizagem e ensino: uma aproximação necessária à aula de Geografia. In: TONINI, I. M. (Org.). O ensino de Geografia e suas composições curriculares. Porto Alegre: UFRGS, 2011. p. 19-27.

MONBEIG, P. Estudos Geográficos. Boletim Geográfico, Rio de Janeiro, v. 1, n. 11, p. 7-11, fev. 1944.

MONBEIG, P. A Geografia no ensino secundário. Boletim Geográfico, Rio de Janeiro, v. 3, n. 26, p. 163-171, maio 1945.

MONBEIG, P. A Geografia no Ensino Secundário. Boletim Geográfico, Rio de Janeiro, v. 13, n. 127 , p. 423-432, jul./ago. 1955.

MORIN, E. O método 4: as ideias. Habitat, vida, costumes, organização. Porto Alegre: Sulina, 2011.

MORY, F. Trabalhos práticos de Geografia. Boletim Geográfico, Rio de Janeiro, v. 5, n. 53, p. 572-574, ago. 1947. 
NIETZSCHE, F. Sobre verdade e mentira no sentido extra-moral (1873). In: NIETZSCHE, F. Obras incompletas. São Paulo: Nova Cultural, 1999. p. 31-38.

NIETZSCHE, F. A gaia ciência. São Paulo: Rideel, 2004.

PINTO, M. M. V. Orientação metodológica para uso do atlas geográfico escolar. Boletim Geográfico, Rio de Janeiro, v. 22, n. 178, p. 114-120, jan./fev. 1964.

PONTUSCHKA, N. N. O conceito de estudo do meio transforma-se... em tempos diferentes, em escolas diferentes, com professores diferentes. In: VESENTINI, J. W. (Org.). O ensino de Geografia no século XXI. Campinas: Papirus, 2004. p. 249-288.

PRADO, E. D. V. Didática da Geografia. Boletim Geográfico, Rio de Janeiro, v. 14, n. 133, p. 392-394, jul./ago. 1956.

PRÉVE, O. da S. D. A participação do Boletim Geográfico do IBGE na produção da metodologia do ensino da Geografia. Dissertação (Mestrado em Educação - Metodologia de Ensino) - Faculdade de Educação, UNICAMP. Campinas, 1989.

QUINTIERRE, L. Leitura de mapas e de fotografias: Bloco-diagrama. Boletim Geográfico, Rio de Janeiro, v. 5, n. 57, p. 1022-1029, dez. 1947.

REEDER, E. O espírito do ensino moderno da Geografia. Boletim Geográfico, Rio de Janeiro, v. 8, n. 93, p. 1111-1115, dez. 1950.

RESENDE, M. S. O saber do aluno e o ensino de Geografia. In: VESENTINI, J. W. (Org.). Geografia e ensino: textos críticos. Campinas, SP: Papirus, 1993. p. 83-115.

VESENTINI, J. W. Realidades e perspectivas do ensino de Geografia no Brasil. In: VESENTINI, J. W. (org.). O ensino de Geografia no século XXI. Campinas: Papirus, 2004. p. 219-248.

VESENTINI, J. W. Repensando a Geografia Escolar para o Século XXI. São Paulo: Plêiade, 2009.

WEISS, A. B. O problema da motivação no ensino da Geografia. Boletim Geográfico, Rio de Janeiro, v. 20, n. 168, p. 297-303, maio/jun. 1962.

ZARUR, J. A Geografia no curso secundário. Revista Brasileira de Geografia, Rio de Janeiro, v. 3, n. 2, p. 227-269, abr./jun. 1941.

Texto recebido em 18 de agosto de 2017. Texto aprovado em 21 de dezembro de 2017. 